\title{
Prognostic factors predicting a fatal outcome in HIV-negative children with neurotuberculosis
}

\author{
Murilo Gimenes Rodrigues', Jaime Lin', Marcelo Rodrigues Masruha', \\ Luiz Celso Pereira Vilanova', Thais Soares Cianciarullo Minett²
}

\begin{abstract}
Objective: To identify prognostic factors predicting a fatal outcome in HIV-negative children with neurotuberculosis based on clinical, epidemiological, and laboratory findings. Method: The clinical records of all in-patients diagnosed with neurotuberculosis from 1982 to 2005 were evaluated retrospectively. The following prognostic parameters were examined: gender, age, close contact with a tuberculosis-infected individual, vaccination for bacillus Calmette-Guérin, purified protein derivative (PPD) of tuberculin results, concomitant miliary tuberculosis, seizures, CSF results, and hydrocephalus. Results: One hundred fortyone patients diagnosed with neurotuberculosis were included. Seventeen percent of the cases resulted in death. The factors that were correlated with a negative outcome included lack of contact with a tuberculosis-infected individual, negative PPD reaction, coma, and longer hospitalisation time. A multiple logistic regression analysis was performed to identify which of these factors most often resulted in death. Conclusion: Coma at diagnosis, lack of tuberculosis contact, and a non-reactive PPD were the most important predictors of fatality in patients with neurotuberculosis.
\end{abstract}

Key words: tuberculosis, meningitis, central nervous system, prognosis, child.

Fatores prognósticos de letalidade da neurotuberculose em crianças HIV-negativas

\section{RESUMO}

Objetivo: Identificar elementos prognósticos para a letalidade da neurotuberculose na criança, a partir das manifestações clínicas, dados epidemiológicos e laboratoriais. Método: Registros de pacientes internados durante o período de 1982 a 2005 foram retrospectivamente avaliados. Os elementos prognósticos considerados foram: sexo, idade, história de contato íntimo com indivíduo com tuberculose, vacinação com o bacilo de Calmette-Guérin (BCG), teste tuberculínico (PPD), concomitância de tuberculose miliar, convulsões, resultados da análise do LCR e presença de hidrocefalia. Resultados: 141 pacientes com diagnóstico de neurotuberculose foram incluídos. Dezessete por cento dos pacientes foram a óbito. Os fatores associados ao óbito foram história negativa de contágio, ausência de reatividade ao teste de PPD, coma e tempo de internação prolongado. Análise por regressão logística múltipla foi usada para investigar as relações entre os elementos prognósticos e o desfecho óbito. Conclusão: Os fatores prognósticos na previsão de óbito nos pacientes com neurotuberculose foram a presença de coma no momento do diagnóstico, a ausência de história de contágio e a ausência de reação ao PPD.

\section{Correspondence}

Murilo Gimenes Rodrigues

Setor de Neurologia Infantil

Depto. de Neurologia e Neurocirurgia

Universidade Federal de São Paulo

Rua Botucatu 720

04023-900 São Paulo SP - Brasil

E-mail: mgimenes@npd.ufes.br

Received 31 January 2010

Received in final form 20 March 2010

Accepted 26 March 2010
Tuberculosis remains one of the most severe infectious diseases and more than eight million new cases are diagnosed worldwide each year. The disease is especially prevalent in developing countries affected by poverty, malnutrition, and over- 
population ${ }^{1}$. In addition, the human immunodeficiency virus (HIV) has caused a resurgence of tuberculosis ${ }^{2,3}$.

According to the World Health Organisation, 22 countries are responsible for more than $80 \%$ of tuberculosis cases. Among these countries, Brazil occupies the $14^{\text {th }}$ position, reporting more than 60 cases per 100,000 inhabitants, 50 million infected people, 92,000 new cases, and 8,400 deaths annually $y^{4}$.

Although pulmonary tuberculosis is more frequent, neurotuberculosis is considered a more severe form because even when treated, it often leads to death or neurological sequelae ${ }^{5,6}$.

Important prognostic indicators of neurotuberculosis include age (especially very young or old individuals), clinical stage at diagnosis, presence of neurological deficits, presence of other forms of tuberculosis, presence of other diseases, malnutrition, seizures, and resistance to tuberculosis treatment ${ }^{5}$.

However, the clinical manifestations of tuberculosis differ in children and adults. In children, a closed caseous lesion is commonly the primary infection. Children also present extrapulmonary cases more frequently and exhibit a higher incidence of miliary dissemination ${ }^{7}$.

This study aims to identify prognostic factors that may predict a fatal outcome in HIV-negative children who suffer from tuberculosis based on clinical, epidemiological, and laboratory findings.

\section{METHOD}

The study was performed at the Nossa Senhora da Glória Children's Hospital in Vitória ES, Brazil. The clinical records of all in-patients diagnosed with neurotuberculosis from 1982 to 2005 were evaluated retrospectively. We used the diagnostic criteria for neurotuberculosis proposed and validated by Ahuja et al. ${ }^{8}$ and Doerr et al. ${ }^{9}$.

Patients with a definitive or probable diagnosis of neurotuberculosis were included ${ }^{5}$. A definitive diagnosis was defined by either the presence of alcohol acid-resistant bacillus in the cerebrospinal fluid (CSF), a positive culture for Mycobacterium tuberculosis, or a conclusive postmortem examination. A probable diagnosis was defined by neurologically abnormal signs and symptoms accompanied by two or more of the following conditions: [A] CSF with pleocytosis and predominance of lymphocytes (characteristic of the neutrophilic dominance of early tuberculosis) without evidence of other infection; [B] previous or concomitant contact (either intradomiciliary or otherwise significant) with a tuberculosis-infected individual, or a positive culture for Mycobacterium tuberculosis from any part of the body other than the central nervous system; $[\mathrm{C}]$ radiological evidence of pulmonary tuberculosis; [D] a reactive tuberculin test without a vaccine scar; and [E] a cranial computed tomography (CT) scan compatible with tuberculous meningoencephalitis (i.e., a CT showing two or more of the following features: exudates in the basal cisterns or sylvian sulcus, hydrocephalus, tuberculomas, infarcts, or gyral enhancement). Since 1986, when ELISA for HIV becomes available to us, all patients were tested for HIV infection and positive cases were excluded.

The following prognostic parameters were examined: gender, age, previous or concomitant contact with a tuberculosis-infected individual (either intradomiciliary or other prolonged contact), vaccination for bacillus Calmette-Guérin (BCG) (this immunisation is required in Brazil and can be confirmed by the presence of a vaccine scar on the right deltoid or by cross-referencing with a vaccine register), presence of tuberculin purified protein derivative (PPD), concomitant miliary tuberculosis, seizures, and hydrocephalus. A CSF analysis was also performed, and the results were statistically analyzed.

To classify the severity of the disease in our patients, we used the clinical stages defined by the British Medical Research Council (BMRC): stage I - patients with general symptoms (fever, anorexia, headache, and vomiting); stage II - patients with meningeal irritation accompanied by a diminished level of consciousness; and stage III - patients with coma, decortication, or descerebration ${ }^{5}$.

RT23 PPD tuberculin was used and applied following the Mantoux technique via an intradermic route in the middle third of the anterior forearm. The dose was $0.1 \mathrm{ml}$, which is equivalent to $2 \mathrm{TU}$ (tuberculin units). The larger transverse diameter of the indurate palpable area was measured with a millimetre ruler 72 to 96 hours after tuberculin application. The result was recorded in millimetres: up to $4 \mathrm{~mm}$ (non-reactive); 5 to $9 \mathrm{~mm}$ (weak reactive); $10 \mathrm{~mm}$ or more (strong reactive ${ }^{10}$.

A Chi-square $\left(\chi^{2}\right)$ or Fisher statistical test was used to compare categorical prognostic factors between surviving and deceased patients. A Student's t-test ( $\mathrm{t}$ ) was used to compare the mean values of the continuous measurements. A multiple logistic regression analysis was used to investigate the relationship between fatality and the prognostic factors that were found to be significant in the univariate analysis. Missing data were excluded, and outliers were not removed from the model. The odds ratios (OR) with 95\% confidence intervals (CI) are reported. All tests were two tailed; a p-value $<0.05$ was considered to indicate a statistically significant difference. All statistical analyses were conducted on a personal computer with the SPSS for Windows (version 11.5.1) software package.

The hospital ethics commission of the Federal University of São Paulo and the technical directive department of the Nossa Senhora da Glória Children's Hospital approved this study under registration number 0796/07. 


\section{RESULTS}

One hundred forty-one cases of children with neurotuberculosis from 1982 to 2005 were reviewed. A definitive diagnosis was established in twenty-three patients (16\%); the remaining cases (84\%) were children with a probable diagnosis.

The incidence age varied from 3 to 156 months (median 24 months). Among the 141 cases, 87 (62\%) were boys, 68 (48\%) had been previously immunised with the BCG vaccine, 109 (77\%) reported either an intradomiciliary or other significant contact with a tuberculosis-infected patient, and 27 (19\%) presented concomitant miliary tuberculosis. The mean length of hospitalisation varied from 2 to 270 days (median 60 days). The main clinical findings are listed in Table 1.

\section{CSF analysis}

The Koch bacillus was identified in the CSF of 23 (16\%) of the children. Of those, 9 (39\%) presented a positive CSF culture, 9 (39\%) presented a positive direct examination, and $5(22 \%)$ presented positive results using both methods.

The mean \pm SD of the CSF protein, glucose, and cell count was 143.2 (17-1034) mg/100 ml, 34.9 (0-100) $\mathrm{mg} / 100 \mathrm{ml}$, and 325.1 (10-5120) cells $/ \mathrm{mm}^{3}$, respectively. A hundred-fourteen (81\%) patients presented CSF protein readings of above $40 \mathrm{mg} / 100 \mathrm{ml}$ and 109 (77\%) presented CSF glucose readings lower than $50 \mathrm{mg} / 100 \mathrm{ml}$.

\section{Neuroimaging}

Computed tomography scans were performed on 62 (44\%) of the patients. Among these scans, 54 (87\%) disclosed abnormalities. Hydrocephalus was the most prevalent abnormality (79\% of the scans), followed by infarct areas (18\%) and tuberculomas (16\%). Interestingly, isolated tuberculomas were found in 11 (17.7\%) of the scans, and
Table 1. Frequency of the signs and symptoms of neurotuberculosis patients at the time of admission.

\begin{tabular}{ll}
\hline Signs and symptoms & $\%$ \\
\hline Fever & 96 \\
Nuchal rigidity & 79 \\
Vomiting & 63 \\
Spasticity & 52 \\
Drowsiness & 50 \\
Anorexia & 49 \\
Seizures & 46 \\
Apathy & 45 \\
Cough & 38 \\
Headache & 36 \\
Weight loss & 33 \\
Irritability & 32 \\
Cranial nerve palsies & 30 \\
Stupor & 19 \\
Slow photomotor reflex & 18 \\
Diarrhoea & 16 \\
Coma & 13 \\
Constipation & 9 \\
\hline & \\
\hline
\end{tabular}

isolated infarct areas were found in $2(3 \%)$. One patient presented with concomitant tuberculomas and infarct areas.

\section{PPD test}

The PPD test was performed during the first week of hospitalisation. Of the 141 patients, 69 (49\%) of the patients were non-reactive, 14 (10\%) were weakly reactive, and 58 (41\%) were strongly reactive.

Among the children with previous immunisation, the PPD test reactivity did not vary significantly: 70 (50\%) were non-reactive, $18(13 \%)$ were weakly reactive, and 53 $(37 \%)$ were strongly reactive $\left(\chi^{2}(2)=6.0 ; \mathrm{p}=0.050\right)$.

Table 2. Comparison of prognostic factor frequencies in surviving and deceased neurotuberculosis patients. Factors include previous BCG immunisation, positive tuberculosis contact, miliary tuberculosis, PPD reactivity, CT abnormalities, coma, epileptic seizures, and CSF polymorphonuclear predominance.

\begin{tabular}{lccccc}
\hline Prognostic factors & $\mathrm{n}$ & Survivors (\%) & Deceased (\%) & $\chi^{2}(1)$ & $\mathrm{p}$ \\
\hline BCG immunisation & 141 & 46 & 58 & 1.18 & 0.277 \\
Contact & 141 & 80 & 58 & 5.38 & $0.020^{*}$ \\
Miliary tuberculosis & 141 & 20 & 12 & - & $0.569^{+}$ \\
PPD reactivity & 128 & 54 & 29 & 4.61 & $0.032^{*}$ \\
CT abnormalities & 62 & 85 & 100 & - & $0.590^{+}$ \\
Coma & 141 & 6 & 47 & 28.40 & $<0.001^{*}$ \\
Seizures & 141 & 43 & 62 & 3.13 & 0.077 \\
PMN predominance & 140 & 27 & 29 & 0.06 & 0.807 \\
\hline
\end{tabular}

*Significant; ${ }^{+}$Fisher statistical test; BCG: bacillus Calmette-Guérin; PPD: purified protein derivative; CSF: cerebrospinal fluid; PMN: polymorphonuclear; CT: computed tomography. 
Table 3. Comparison of the prognostic factor mean values among surviving and deceased neurotuberculosis patients.

\begin{tabular}{|c|c|c|c|c|c|c|c|c|c|c|}
\hline \multirow{3}{*}{$\begin{array}{l}\text { Prognostic factors } \\
\text { Age }\end{array}$} & \multicolumn{4}{|c|}{$($ mean $\pm \mathrm{SD})$} & & & & \multirow[b]{2}{*}{$\mathrm{t}$} & \multirow[b]{2}{*}{ DF } & \multirow[b]{2}{*}{$\mathrm{p}$} \\
\hline & \multicolumn{2}{|c|}{ Survivors } & \multicolumn{2}{|c|}{ Deceased } & \multicolumn{3}{|c|}{ 95\% Cl (mean difference) } & & & \\
\hline & 43.8 & 45.8 & 48.4 & 44.5 & -15.2 & to & 24.4 & 0.5 & 139 & 0.646 \\
\hline Length of hospitalisation (days) & 45.7 & 53.9 & 72.0 & 49.4 & 4.0 & to & 48.5 & 2.3 & 139 & $0.021^{*}$ \\
\hline Cellularity & 283.6 & 379.6 & 333.7 & 555.9 & -185.2 & to & 285.4 & 0.4 & 138 & 0.674 \\
\hline CSF protein & 143.6 & 146.2 & 143.1 & 150.7 & -67.0 & to & 66.0 & 0.0 & 138 & 0.987 \\
\hline CSF glucose & 30.1 & 19.6 & 35.9 & 22.5 & -3.9 & to & 15.6 & 1.2 & 138 & 0.238 \\
\hline
\end{tabular}

*Significant; SD: standard deviation; Cl: confidence interval; DF: degrees of freedom; CSF: cerebrospinal fluid.

Table 4. Likelihood of death based on results from the multiple logistic regression analysis using the prognostic factors as independent variables.

\begin{tabular}{lccccccccc}
\hline Prognostic factors & B & SE & Wald $\chi^{2}$ & OR & & 95\% Cl & (OR) & p \\
\hline Coma & -2.11 & 0.53 & 15.65 & 0.12 & 0.04 & to & 0.35 & $<0.001^{*}$ \\
Hospitalisation time & -0.01 & 0.01 & 3.45 & 0.99 & 0.97 & to & 1 & 0.063 \\
Absence of contact & 1.24 & 0.58 & 4.6 & 3.47 & 1.11 & to & 10.82 & $0.032^{*}$ \\
Absence of PPD reactivity & 0.81 & 0.5 & 2.59 & 2.25 & 0.84 & to & 6.05 & 0.108 \\
\hline
\end{tabular}

*Significant; $n$ deceased: $n$ survivors=21:107; SE: standard error; $\chi^{2}$ : chi-square; Cl: confidence interval; OR: odds ratio; PPD: purified protein derivative.

\section{Lethality}

Twenty-four (17\%) patients died. Tables 2 and 3 compare the prognostic parameters of surviving and deceased patients.

The factors associated with a negative outcome were a negative history of contact with a tuberculosis-infected individual, a negative PPD reaction, coma, or a longer hospitalisation time.

A multiple logistic regression analysis was performed to identify which of the preceding factors most often resulted in fatalities (Table 4). We found that coma at the time of hospitalisation and a negative tuberculosis contact history were the factors most strongly correlated with fatality.

The difference in the proportion of deceased patients between the definite (13\%) and probable (18\%) cases was not significant (Fisher exact test, $\mathrm{p}=0.765$ ).

\section{DISCUSSION}

We found that coma at the time of admission, a negative tuberculosis contact history, and a non-reactive PPD were most commonly associated with fatalities in neurotuberculosis patients.

Our series had a low percentage of fatalities (17\%), a result that is similar to data from Mahadevan et al. $(16 \%)^{11}$ and Lee et al. $(10 \%)^{7}$. In our study, most of the patients were in clinical stages I or II as defined by the BMRC scale, which may explain the low percentage of lethal cases.

Despite these results, the high lethality of neurotuberculosis is what makes it more severe than other forms of tuberculosis ${ }^{12}$. Some authors have tried to identify the prognostic factors of neurotuberculosis ${ }^{13-15}$. The level of consciousness at the time of admission or at the time that a specific therapy is established is the main prognostic factor that predicts disease lethality and sequelae ${ }^{16,17}$. In our study, more than $60 \%$ of the 24 patients who died were in coma when hospitalised.

Among our patients, 77\% had a history of close contact with an individual who was a confirmed tuberculosis sufferer. In other studies, the history of close contact with tuberculosis varies widely from 20 to $75 \%{ }^{18-20}$. Absence of close contact with a tuberculosis-infected individual, however, tends to be strongly correlated with fatalities. In our study, $15 \%$ of the patients had a negative history of close contact and 30\% of these patients eventually died. The absence of close contact may be related to higher fatalities because of a delay in establishing an appropriate treatment protocol. More than half of our patients began treatment during the first few days of hospitalisation, most of whom reported a positive epidemiological history that caused us to suspect tuberculosis. Another explanation is that these patients could have some kind of immunological deficient mechanisms, being more susceptible to develop neurotuberculosis, even with a small inoculus.

Molavi et al. ${ }^{19}$ and Hosoglu et al. ${ }^{21}$, over a decade later, addressed the importance of contact history as an important and useful epidemiological tool for the early diagnosis of tuberculosis. Their reports, however, failed to correlate this data with the patient's prognosis. While a history of close contact did reduce the time between diagnosis and treatment, in our experience this history is of- 
ten difficult to obtain from the patients or their relatives because of the continuing stigma surrounding tuberculosis and due to ignorance about the disease.

In our study, a non-reactive PPD was found in $63 \%$ of the patients and this was shown to have a negative impact on patient outcomes. A non-reactive PPD would not be unusual if the disease were in an advanced stage, when patients present severe cellular immunity impairment ${ }^{22}$. This may also be explained by a previous deficiency of immune mechanisms. The correlation between a negative prognosis and PPD insensitivity may be a direct consequence of a typical meningeal reaction failure ${ }^{23,24}$. Succi et al. ${ }^{25}$ found that, among 111 children with neurotuberculosis, those with a consistently negative PPD results had more extensive neurological involvement.

CT scans were performed on only $44 \%$ of the patients because many of them were treated between 1982 and 1990, a decade when this resource was largely unavailable in our centre. However, every patient in our study who died presented an abnormal $\mathrm{CT}$ examination that suggested hydrocephalus, infarct areas, or tuberculomas. Tan et al. ${ }^{26}$ examined a group of 18 patients with neurotuberculosis and found that the presence of hydrocephalus was the only factor associated with a negative prognosis; however, this prognosis was also correlated with a more advanced disease stage.

The high incidence of hydrocephalus in our series reflects the typical physiopathological presentation of neurotuberculosis, which includes a blockage of CSF drainage-especially in the basal cisterns ${ }^{27}$. However, we found only a weak correlation between hydrocephalus and fatalities, perhaps because our patients presented only mild hydrocephalus. Although hydrocephalus is a common feature of neurotuberculosis and is associated with a negative prognosis, early treatment can prevent the progression of ventricular dilatation ${ }^{28}$. If these patients had been diagnosed earlier, the prognosis could potentially have been better ${ }^{29}$.

The presence of seizures has also been correlated with eventual fatality. Paganini et al. ${ }^{30}$ reported that seizures were an important predictor of fatal outcomes in 40 children with tuberculosis. In this report, seizures were manifested late in the disease and were usually associated with more advanced stages of tuberculosis ${ }^{24}$. In our study, however, seizures were not related to death. Importantly, our study only evaluated symptoms after hospitalisation. In contrast with Paganini et al. ${ }^{30}$, who regarded seizure as a late manifestation of tuberculosis, our study found that, after hospitalisation, seizures could be present in any stage of the disease.

The presence of CSF alterations also failed to predict a negative prognosis. Succi et al. ${ }^{25}$ assessed the clinical evo- lution of patients with different intensities of pleocytosis, concluding that CSF alterations increased the likelihood of fatality but noting that this correlation was not statistically significant. In contrast, Singh et al. ${ }^{31}$ found that patients who presented protein concentrations above 200 $\mathrm{mg} / \mathrm{dL}$, glucose lower than $20 \mathrm{mg} / \mathrm{dL}$, and chlorides lower than $650 \mathrm{mg} / \mathrm{dL}$ exhibited a higher incidence of fatality. However, Singh et al. only included adult patients and failed to analyse their data for statistical significance.

In our study, the concomitance of miliary tuberculosis was also not associated with fatality. Succi et al. ${ }^{25}$ concluded that the presence of radiological alterations, which indicate the presence of miliary tuberculosis, did not increase the likelihood of death. Our study used the same radiological criteria to determine the presence of miliary tuberculosis. It is possible that those patients who survived long enough to present an image that was detectable and indicated miliary dissemination had a stronger immune response. Thus, these patients exhibited a survival rate similar to those patients without miliary dissemination. In contrast, Paganini et al..$^{30}$ reported that extra-meningeal foci of tuberculous meningitis were predictors of fatality. They hypothesised that the detection of extra-meningeal tuberculosis in neurotuberculosis patients may be an important tool for early diagnosis and may lead to a better prognosis.

Rodrigues et al. ${ }^{32}$ argued that BCG immunisation may protect children against the most severe forms of tuberculosis and result in a better prognosis. In our study, BCG immunisation did not affect the prognosis of neurotuberculosis. However, because all of the patients enrolled in our study already presented a severe form of the disease, we were unable to evaluate whether BCG immunisation affects the prognosis of tuberculosis by protecting against the most severe forms. Interestingly, more than half of our patients had been immunised with BCG but still developed neurotuberculosis, calling into question the ability of the BCG vaccine to protect against severe forms of tuberculosis.

Our retrospective study was limited by the fact that neuroimaging was not performed with all patients. Additionally, our diagnoses of tuberculosis were based on clinical criteria and we failed to secure microbiological confirmation.

In conclusion, coma at the time of hospitalisation and a negative history of close contact were the most important prognostic factors indicating a fatal outcome among HIV-negative children with neurotuberculosis. Because it is difficult to diagnosis neurotuberculosis, any patient diagnosed with an infectious disease of unknown aetiology and presenting neurological symptoms should be proactively tested for tuberculosis. 


\section{REFERENCES}

1. Schachter EN. Tuberculosis: a global problem at our doorstep. Chest 2004; 126:1724-1725.

2. Corbett EL, Watt $\mathrm{CJ}$, Walker N, et al. The growing burden of tuberculosis: global trends and interactions with the HIV epidemic. Arch Intern Med 2003;163:1009-1021.

3. Snider DE Jr., Roper WL. The new tuberculosis. N Engl J Med 1992;326: 703-705.

4. WHO. Global tuberculosis control: epidemiology, strategy, financing - WHO report 2009. 2009.

5. Hosoglu S, Geyik MF, Balik I, et al. Predictors of outcome in patients with tuberculous meningitis. Int J Tuberc Lung Dis 2002;6:64-70.

6. Girgis NI, Sultan Y, Farid Z, et al. Tuberculosis meningitis, Abbassia Fever Hospital-Naval Medical Research Unit No. 3-Cairo, Egypt, from 1976 to 1996. Am J Trop Med Hyg 1998;58:28-34.

7. Lee LV. Neurotuberculosis among Filipino children: an 11 years experience at the Philippine Children's Medical Center. Brain Dev 2000;22:469-474.

8. Ahuja GK, Mohan KK, Prasad K, Behari M. Diagnostic criteria for tuberculous meningitis and their validation. Tuber Lung Dis 1994;75:149-152.

9. Doerr CA, Starke JR, Ong LT. Clinical and public health aspects of tuberculous meningitis in children. J Pediatr 1995;127:27-33.

10. Bailey WC, Thompson DH, Greenberg HB. A technique for standardizing the jet injector and Mantoux tuberculin skin tests. Public Health Rep 1974; 89:465-467.

11. Mahadevan B, Mahadevan S, Serane VT. Prognostic factors in childhood tuberculous meningitis. J Trop Pediatr 2002;48:362-365.

12. Gusmao Filho FA, Marques HH, Marques-Dias MJ, Ramos SR. [Central nervous system tuberculosis in children: 1. Clinical and laboratorial presentation]. Arq Neuropsiquiatr 2001;59:71-76.

13. Misra UK, Kalita J, Roy AK, Mandal SK, Srivastava M. Role of clinical, radiological, and neurophysiological changes in predicting the outcome of tuberculous meningitis: a multivariable analysis. J Neurol Neurosurg Psychiatry 2000;68:300-303.

14. Ramachandran P, Duraipandian M, Nagarajan M, Prabhakar R, Ramakrishnan CV, Tripathy SP. Three chemotherapy studies of tuberculous meningitis in children. Tubercle 1986;67:17-29.

15. Saitoh A, Pong A, Waecker NJ, Jr., Leake JA, Nespeca MP, Bradley JS. Prediction of neurologic sequelae in childhood tuberculous meningitis: a review of 20 cases and proposal of a novel scoring system. Pediatr Infect Dis J 2005;24:207-212

16. Farinha NJ, Razali KA, Holzel H, Morgan G, Novelli VM. Tuberculosis of the central nervous system in children: a 20-year survey. J Infect 2000;41:61-68.

17. Nunes C, Cunha S, Gomes I, Lucena R, Moraes D, Melo A. [Prognostic fac- tors of tuberculous meningoencephalitis lethality]. Arq Neuropsiquiatr 1998:56:772-777.

18. Yeo IK, Tannenbaum T, Scott AN, et al. Contact investigation and genotyping to identify tuberculosis transmission to children. Pediatr Infect Dis J 2006;25: 1037-1043.

19. Molavi A, LeFrock JL. Tuberculous meningitis. Med Clin North Am 1985;69: 315-331.

20. Bateman DE, Newman PK, Foster JB. A retrospective survey of proven cases of tuberculous meningitis in the Northern Region, 1970-1980. J R Coll Physicians Lond 1983;17:106-110.

21. Hosoglu S, Ayaz C, Geyik MF, Kokoglu OF, Ceviz A. Tuberculous meningitis in adults: an eleven-year review. Int J Tuberc Lung Dis 1998;2:553-557.

22. Boras Z, Juretic A, Rudolf M, Uzarevic B, Trescec A. Cellular and humoral immunity to purified protein derivative (PPD) in PPD skin reactive and nonreactive patients with pulmonary tuberculosis: comparative analysis of antigen-specific lymphocyte proliferation and IgG antibodies. Croat Med J 2002;43:301-305.

23. Waecker NJ Jr., Connor JD. Central nervous system tuberculosis in children a review of 30 cases. Pediatr Infect Dis J 1990;9:539-543.

24. Illingworth RS. Miliary and meningeal tuberculosis; difficulties in diagnosis, Lancet 1956;271:646-649.

25. Succi RCM. Meningoencefalite tuberculosa na infância: estudo de $358 \mathrm{ca}-$ sos. Aspectos clínicos, laboratoriais e fatores prognósticos. Tese. Universidade de São Paulo. São Paulo, 1990

26. Tan EK, Chee MW, Chan LL, Lee YL. Culture positive tuberculous meningitis: clinical indicators of poor prognosis. Clin Neurol Neurosurg 1999;101: 157-160.

27. Altunbasak S, Alhan E, Baytok V, Aksaray N, Yuksel B, Onenli N. Tuberculous meningitis in children. Acta Paediatr Jpn 1994;36:480-484.

28. Schoeman JF, Van ZyI LE, Laubscher JA, Donald PR. Serial CT scanning in childhood tuberculous meningitis: prognostic features in 198 cases. J Child Neurol 1995;10:320-329.

29. Gusmao Filho FA, Marques-Dias MJ, Marques HH, Ramos SR. [Central nervous system tuberculosis in children: 2 . Treatment and outcome]. Arq Neuropsiquiatr 2001;59:77-82.

30. Paganini H, Gonzalez F, Santander C, Casimir L, Berberian G, Rosanova MT. Tuberculous meningitis in children: clinical features and outcome in 40 cases. Scand J Infect Dis 2000:32:41-45.

31. Singh NK, Singh P, Tripathi K, Srivastava PK, Singh DS. Prognostic factors and sequelae of tuberculous meningitis in adults. J Indian Med Assoc 1985; 83:50-53.

32. Rodrigues $L C$, Diwan VK, Wheeler JG. Protective effect of $B C G$ against tuberculous meningitis and miliary tuberculosis: a meta-analysis. Int J Epidemiol 1993;22:1154-1158. 